\title{
Early failure of the Trifecta GT bioprostheses
}

Lise Tchouta, MD, MSc, Daniel Liesman, BS, Karen Kim, MD, MSc, and Shinichi Fukuhara, MD, Ann Arbor, Mich

From the Department of Cardiac Surgery, University of Michigan Health Systems, Ann Arbor, Mich.

Disclosures: The authors reported no conflicts of interest.

The Journal policy requires editors and reviewers to disclose conflicts of interest and to decline handling or reviewing manuscripts for which they may have a conflict of interest. The editors and reviewers of this article have no conflicts of interest.

Received for publication July 29, 2020; revisions received July 29, 2020; accepted for publication Aug 10, 2020; available ahead of print Aug 12, 2020.

Address for reprints: Shinichi Fukuhara, MD, Department of Cardiac Surgery, University of Michigan, 1500 E. Medical Center Dr, Ann Arbor, MI 48109 (E-mail: fukuhara@med.umich.edu).

JTCVS Techniques 2020;4:106-8

2666-2507

Copyright $\Subset 2020$ The Authors. Published by Elsevier Inc. on behalf of The American Association for Thoracic Surgery. This is an open access article under the CC BY-NC-ND license (http://creativecommons.org/licenses/bync-nd/4.0/).

https://doi.org/10.1016/j.xjtc.2020.08.010

Trifecta bioprosthetic valves with Glide Technology, also known as Trifecta GT (Abbott Vascular, Santa Clara, Calif), were approved by the US Food and Drug Administration in 2016. These are stented valves with a bovine pericardial sheet externally mounted on a titanium stent. There were several reports of early failure involving the firstgeneration Trifecta that were related to structural valve degeneration secondary to leaflet calcification, pannus formation, and cusps tear presenting less than 7 years after implantation. ${ }^{1-4}$ Improvement in the design of Trifecta GT was implemented in response to those vulnerabilities, including Linx anticalcification technology and the Glide Technology for ease of implantation and minimal distortion during implantation. ${ }^{3}$ However, despite these changes, we report here 3 cases of early failure involving the newer Trifecta GT.

\section{CLINICAL SUMMARY}

Since the use of Trifecta GT in 2016, we have encountered 3 cases of early failure. Two were implanted at University of Michigan and one at an outside facility. In our own program, 106 Trifecta GTs were implanted between November 2016 and December 2017. The cumulative incidence of valve failure represented $3.3 \%$ at 3.5 years after accounting for competing events of prosthetic valve endocarditis $(\mathrm{n}=1)$ and non-cardiac deaths $(\mathrm{n}=5)$.

Written informed consent for publication was obtained from each patient. The mean age at the Trifecta GT implantation was 56.7 years, and 2 were men. Only patient 1 had hypertension and diabetes mellitus. The other 2 patients were otherwise healthy. All patients had a bicuspid aortic valve (Sievers type 1 with fusion of the left and right cusps in all cases). Two were pure stenosis and one was mixed stenosis and aortic insufficiency pathology. Essential clinical data regarding the index Trifecta GT implantation
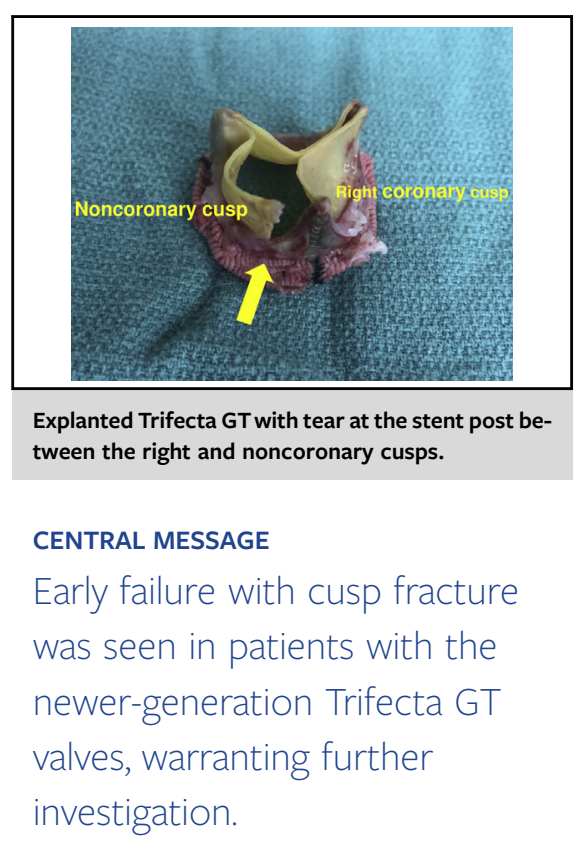

See Commentary on page 109.

procedure, valve failure, and explantation procedure are summarized in Table 1. These Trifecta GTs were implanted by 3 different surgeons. Valve sizes ranged from 23 to $25 \mathrm{~mm}$, and Cor-Knot (LSI Solutions, Victor, NY) was used in one case. None of implanted valves was oversized. Postoperative course in each case was uneventful.

All patients presented with heart failure with newly diagnosed severe aortic insufficiency ranging from 1.9 to 3.2 years after the index procedure. No patients demonstrated clinical signs suspicious for endocarditis. However, due to the extremely sooner-than-expected failure, blood cultures were drawn in all patients to rule out endocarditis and came back negative. All patients underwent redo surgical aortic valve replacement.

Of note, intraoperative findings were consistent with a detached cusp at the stent post between the noncoronary and the right coronary cusps (Figure 1) in all cases. Case 1 also had circumferential pannus formation without significant transvalvular gradient. Leaflets were still pliable without calcifications. Due to the unexpected failure mode with extremely short durability, the explanted Trifecta GTs were sent for culture to rule out occult prosthetic valve endocarditis in 2 patients and both came back 
TABLE 1. Relevant clinical characteristics at index Trifecta GT valve implantation and explantation

\begin{tabular}{|c|c|c|c|}
\hline Patient & 1 & 2 & 3 \\
\hline Age/sex & $62 \mathrm{y} / \mathrm{male}$ & $61 \mathrm{y} / \mathrm{female}$ & $47 \mathrm{y} / \mathrm{male}$ \\
\hline Year of Trifecta GT implant & 2016 & 2016 & 2016 \\
\hline Original valve pathology & Bicuspid, AS & Bicuspid, AS & Bicuspid, AS/AI \\
\hline Body surface area, $\mathrm{m}^{2}$ & 2.27 & 1.52 & 1.87 \\
\hline Ascending aorta diameter, $\mathrm{mm}$ & 35 & 27 & 46 \\
\hline Sinus of Valsalva diameter, $\mathrm{mm}$ & 36 & 31 & 38 \\
\hline Annulus diameter, mm & $28 \times 19$ & $23 \times 21$ & $26 \times 23$ \\
\hline Trifecta GT size, $\mathrm{mm}$ & 25 & 23 & 25 \\
\hline Cor-Knot use & No & No & Yes \\
\hline Pledget use & Yes & Yes & Yes \\
\hline Annulus enlargement & Nicks & No & Nicks \\
\hline Other concomitant procedures & No & No & Ascending aortic replacement \\
\hline Intraoperative AI & None & None & None \\
\hline $\begin{array}{l}\text { Latest follow-up } \\
\text { echocardiography before } \\
\text { failure }\end{array}$ & $\begin{array}{c}\text { At } 1.6 \mathrm{y} \\
\text { Mean gradient } 9 \mathrm{~mm} \mathrm{Hg} \\
\text { No AI }\end{array}$ & $\begin{array}{c}\text { At } 1.4 \text { y } \\
\text { Mean gradient } 7 \mathrm{~mm} \mathrm{Hg} \\
\text { No AI }\end{array}$ & $\begin{array}{l}\text { At } 3 \text { mo } \\
\text { No AI }\end{array}$ \\
\hline Year of Trifecta GT explant & 2020 & 2019 & 2018 \\
\hline $\begin{array}{l}\text { Duration between implantation } \\
\text { and failure, y }\end{array}$ & 3.2 & 2.3 & 1.9 \\
\hline Failure mode & AI & AI & AI \\
\hline Mean gradient, mm $\mathrm{Hg}$ & 14 & 16 & 20 \\
\hline Notable intraoperative findings & $\begin{array}{l}\text { Detached cusp at the stent post } \\
\text { between the noncoronary and } \\
\text { the right coronary cusps. } \\
\text { Circumferential pannus } \\
\text { formation. }\end{array}$ & $\begin{array}{l}\text { Detached cusp at the stent post } \\
\text { between the noncoronary and } \\
\text { the right coronary cusps. }\end{array}$ & $\begin{array}{l}\text { Detached cusp at the stent post } \\
\text { between the noncoronary and } \\
\text { the right coronary cusps. }\end{array}$ \\
\hline $\begin{array}{l}\text { Intraoperative culture of the failed } \\
\text { Trifecta GT }\end{array}$ & Negative & Not obtained & Negative \\
\hline
\end{tabular}

$A S$, Aortic stenosis; $A I$, aortic insufficiency; GT, Glide Technology.

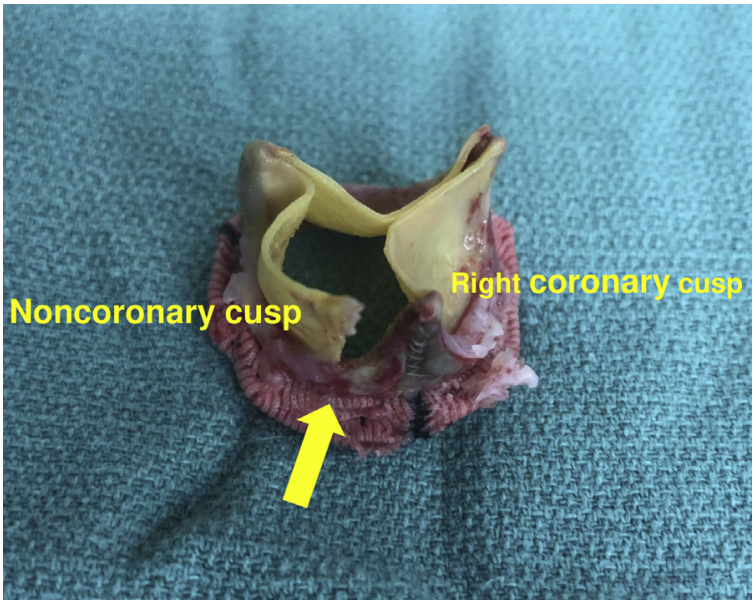

FIGURE 1. An intraoperative photograph of an explanted 25-mm Trifecta GT (Abbott Vascular, Santa Clara, Calif). There was a detached cusp with a large tear (yellow arrow) at the stent post between the noncoronary cusp and the right coronary cusp. There was no evidence of vegetation or any findings suggestive of prosthetic valve endocarditis. negative. All patients had an unremarkable postoperative course.

\section{DISCUSSION}

To the best of our knowledge, this represents the first report describing early failure of the newer-generation Trifecta GT. Although an increasing number of studies regarding early failure of the Trifecta have been reported, ${ }^{1-4}$ these are exclusively from the results of the first-generation Trifecta. Importantly, the follow-up period of studies with favorable Trifecta results was up to 6 years, whereas studies cautioning the Trifecta durability had more than 7-year follow-up periods. ${ }^{2,4}$ In our previous investigation, structural valve degeneration appeared to have occurred abruptly between 5 and 7 years. ${ }^{2}$ Some investigators suggest these mixed results might be due to the implant technique causing excessive pressure on the strut base, leading to weakening of the leaflet, oversizing of the valve, or improper Cor-Knot usage causing contact with the 
pericardium over time..$^{5}$ As mentioned in the present report, these index cases were performed by 3 different surgeons. Cor-Knot was used in only one case. Interestingly, the mode of failure and the location of the cusp tear were identical in all cases. These were common findings in the previous first-generation Trifecta studies. ${ }^{2}$

In the present study, no aortic insufficiency was seen on the index intraoperative or follow-up echocardiograms. While no conclusions can be drawn from this small series, we postulate the unique design of the Trifecta GT might be contributing to the early failure. This is likely multifactorial, including externally mounted leaflet design and mechanical abrasion from the aortic wall at a particular location. The location between the right and noncoronary cusps may represent a specific susceptible anatomic location. In this context, further investigation with a control group with other stented bioprostheses using standardized methodology is truly needed.

\section{References}

1. Saxena P, Greason KL, Schaff HV. Early structural valve deterioration of the Trifecta aortic valve biological prosthesis: a word of caution. J Thorac Cardiovasc Surg. 2014;147:e10-1.

2. Fukuhara S, Shiomi S, Yang B, Kim K, Bolling SF, Haft J, et al. Early structural valve degeneration of trifecta bioprosthesis. Ann Thorac Surg. 2020;109:720-7.

3. Eichinger S, Badreldin AMA, Eichinger WB. Early degeneration caused by cusp tear of first-generation trifecta bioprosthesis. Ann Thorac Surg. 2018;106:e297-8.

4. Biancari F, Valtola A, Juvonen T, Husso A, Dahlbacka S, Laakso T, et al. Trifecta versus Perimount Magna Ease aortic valve prostheses. Ann Thorac Surg. February 12, 2020 [Epub ahead of print].

5. Kilic A. Structural valve deterioration with the trifecta: is it the valve or is it implant technique? Ann Thorac Surg. March 5, 2020 [Epub ahead of print]. 